\title{
NOTE
}

\section{Issue-by-Issue Negotiations: The Role of Information and Time Preference}

\author{
Mehmet Bac* \\ Department of Economics, Bilkent University, Bilkent, Ankara, 06533 Turkey \\ and \\ Horst Raff* \\ Department of Economics, Indiana University, Bloomington, Indiana 47405
}

Received August 18, 1994

\begin{abstract}
The alternating offers bargaining game with two pies and incomplete information has a bargaining sequential equilibrium where the "strong" type of the informed player restricts his offer to one pie, leaving it to the other player to make an offer on the second pie. An offer on both pies comes only from the "weak" type of informed player. Hence, an issueby-issue negotiation agenda may arise from signaling considerations. Journal of Economic Literature Classification Number: C78. ๑1996 Academic Press, Inc.
\end{abstract}

\section{INTRODUCTION}

Many bargaining situations involve multiple issues and often they are resolved through an issue-by-issue agenda. A concrete example of multiple-issue bargaining is the purchase of a new car where the parties have to agree, among other things, on a price, a trade-in allowance, and financing. The American Automobile Association (1992, p. 17) recommends that buyers first focus on negotiating the price of the car and only discuss financing, factory rebates, and the trade-in allowance once the price has been agreed upon. This argument may seem a bit puzzling because the issues appear to be almost perfect substitutes, all ultimately determining how much money will change hands. Why then would buyers benefit from a time-consuming issue-by-issue process, instead of negotiating them

\footnotetext{
* We thank Bob Becker and a co-editor for helpful comments and suggestions.
} 
simultaneously and perhaps reaching an agreement right away? What kind of buyer would choose the issue-by-issue negotiations?

Bounded rationality is an obvious reason why parties may choose to settle the issues one by one. The set of issues on the negotiation table may be so complex that it may be beyond human capacity to tackle them all at once. In this paper we provide an alternative explanation emphasizing strategic implications of the choice of the negotiation procedure. ${ }^{1}$ We do this in a multidimensional bargaining model where the parties' offers include the negotiation procedure (issue-by-issue versus complete package). The focus is on the effect of incomplete information about bargaining strength on bargaining strategies. Two players negotiate in a Rubinstein fashion over two pies, each of size one. Information is asymmetric as to the discount factor of one player. $^{2}$ With two possible realizations of the discount factor, we show that this bargaining game has a sequential equilibrium with rationalizing beliefs such that, while a weak (impatient) player prefers negotiating simultaneously over two pies, a strong (patient) player may make an offer on just one pie in order to signal barg aining strength. The uninformed player always makes a combined offer on the two pies, which may include screening the informed player and thus causing delay. Issue-by-issue negotiations may thus arise from signalling considerations.

The paper thus formalizes Schelling's insight concerning multidimensional bargaining and extends Rubinstein's (1985) model by adding a second pie. This extension provides for a greater variety of strategic behavior. Whereas in $\mathrm{Ru}-$ binstein the only way to transmit information consists of screening (the strong player rejects the screening offer, the weak player accepts it), our model also allows the informed player to signal his type. On the other hand, the sequential negotiation procedure can be interpreted as an incomplete contract because the corresponding agreements cover only a subset of all issues. Busch and Horstmann (1992) use this interpretation in a Rubinstein bargaining model with two pies but complete information. The two pies in their model are not both available at the outset but arrive in sequential order and the players have different preferences over the pies. In this setting they show that, if the players' preferences over the two pies are sufficiently heterogeneous, one player prefers a complete contract (a sharing rule over both pies) while the other prefers an incomplete contract (separate negotiations). ${ }^{3}$ We show that issues may be negotiated in a sequential

\footnotetext{
${ }^{1}$ These strategic implications were first noted by Schelling (1956). He writes: "when there are two objects to negotiate, the decision to negotiate them simultaneously or in separate forums at separate times is by no means neutral to the outcome."

${ }^{2}$ Asymmetric information is likely to be a problem in the car-buying example: buyers' guides make it relatively easy for buyers to obtain information on the dealer (his wholesale price and required profit margin) and on the product (reliability, quality of workmanship, resale value). On the other hand, dealers have to try hard to elicit information from the buyers they face. That is, incomplete information is more likely to be a problem for the dealers of new cars than for their customers.
}

${ }^{3}$ Fershtman (1990) shows in a bargaining game similar to that of Busch and Horstmann the 
order even if they are perfect substitutes and bargaining procedures are flexible: the two pies in our model are of equal value to the two players and available from the outset, and players in their turn can make offers on one or both pies. ${ }^{4}$ Our explanation for contract incompleteness thus relies on asymmetric information with the presence of a strong player and a sufficient amount of heterogeneity between the two types of the informed player.

\section{A BARGAINING MODEL WITH TWO PIES AND ASYMMETRIC INFORMATION}

Two players, $\mathrm{A}$ and $\mathrm{B}$, bargain over two pies, $\mathrm{X}$ and $\mathrm{Y}$, each of size one. The bargaining procedure involves alternating offers à la Rubinstein. Offers are represented in terms of Player A's shares: $x$ for pie X, and $y$ for pie Y. We refer to an offer on just one pie as a "single offer" and to an offer on two pies as a "combined offer". The bargaining game begins in period 0 , proceeds in discrete time, and ends if the players reach an agreement on sharing both pies. The players' discounted payoffs from the agreement on pie $\mathrm{X}$ reached at date $t$ are respectively $\delta_{\mathrm{A}}^{t} x$ and $\delta_{\mathrm{B}}^{t}(1-x)$ where $\delta_{i} \in(0,1)$ is Player $i$ 's discount factor. Similarly, for agreements reached at date $t$ on both pies, discounted payoffs are $\delta_{\mathrm{A}}^{t}(x+y)$ and $\delta_{\mathrm{B}}^{t}(2-x-y)$. The two pies are thus perfect substitutes but the players may differ on their discount factors.

If two identical pies are available at the outset and if information is complete, then the players never make a single offer (issues are never negotiated separately). To show this, we compare the equilibrium payoffs corresponding to two bargaining games. Rubinstein (1982) demonstrated that discounted payoffs in the unique subgame-perfect equilibrium (SPE) of the complete information bargaining game (pie of size two, A makes the first offer) are given by the pair

$$
\left(\frac{2\left(1-\delta_{\mathrm{B}}\right)}{1-\delta_{\mathrm{A}} \delta_{\mathrm{B}}} ; \frac{2 \delta_{\mathrm{B}}\left(1-\delta_{\mathrm{A}}\right)}{1-\delta_{\mathrm{A}} \delta_{\mathrm{B}}}\right)
$$

negotiation agenda is not neutral to the outcome. On the other hand, there is a growing literature exemplified by Hart and Moore (1988) and Huberman and Kahn (1988) focusingon the role of renegotiations when contracts are incomplete. These papers treat contract incompleteness as exogenously given. In a different context Spier (1992) demonstrates that incomplete contracts may serve as signals, Her result, however, derives from the existence of transaction costs. Signaling occurs by means of a contract that is more incomplete than it would be if there were no information problems. In our model, there are no transaction costs directly associated with writing a complete contract; incompleteness is a product of the information problem alone.

${ }^{4}$ Perfect substitutability of issues implies that a player is concerned with the complete package, not with the outcome of negotiations on individual issues. As pointed out above, this appears to be the case in negotiations over the price, financing, factory rebates, and trade-in allowance of a new car which can all add up to its total cost. 
This agreement is reached immediately. Suppose now that only single offers are allowed and that Player A moves first. It can easily be shown that in the unique SPE the players' discounted payoffs are

$$
\left(\frac{\left(1-\delta_{\mathrm{B}}\right)\left(1+\delta_{\mathrm{A}}^{2}\right)}{1-\delta_{\mathrm{A}} \delta_{\mathrm{B}}} ; \frac{2 \delta_{\mathrm{B}}\left(1-\delta_{\mathrm{A}}\right)}{1-\delta_{\mathrm{A}} \delta_{\mathrm{B}}}\right) .
$$

In this equilibrium, agreement on the first pie is reached in period 0 , followed by an agreement on the second pie in period 1. Comparing payoffs in (1) with those in (2) reveals that under complete information the players will never restrict their offers to just one pie. ${ }^{5}$

We consider now the incomplete information game where Player $\mathrm{B}$ is uncertain of $\delta_{\mathrm{A}}$, which can take one of two values: $\delta_{H}$ with probability $\pi$ and $\delta_{L}$ with probability $1-\pi$. These probabilities are common knowledge. Player A knows his own discount factor, as well as that of Player B. We associate the discount factor $\delta_{L}\left(\delta_{H}\right)$ with type $A_{L}\left(A_{H}\right)$ of Player A and assume that $\delta_{L}<\delta_{H}$. Strategies are formally defined as follows. Let $\mathcal{S}$ be the set of all feasible offers and let $\mathcal{S}^{t}$ be the set of all sequences $\left(\left(x^{0}, y^{0}\right), \ldots,\left(x^{t-1}, y^{t-1}\right)\right)$ of members of $\mathcal{S}$. Note that $(\varnothing, y),(x, \varnothing)$, and $(\varnothing, \varnothing)$ all belong to $\mathcal{S}$; the first two correspond to single offers while the third means no offer is made. Player A's strategy is a sequence $\alpha=\left\{\alpha^{t}\right\}_{t=0}^{\infty}$ of functions, each assigning an action given a history in $\mathcal{S}^{t}$. That is, $\alpha^{t}: \mathcal{S}^{t} \rightarrow \mathcal{S}$ if $t$ is even, and $\alpha^{t}: \mathcal{S}^{t+1} \rightarrow\{$ Yes, No $\}$ if $t$ is odd. Player B's strategy is defined similarly as a sequence $b=\left\{b^{t}\right\}_{t=0}^{\infty}$ of functions with $b^{t}: \mathcal{S}^{t+1} \rightarrow\{$ Yes, No $\}$ if $t$ is even, and $b^{t}: \mathcal{S}^{t} \rightarrow \mathcal{S}$ if $t$ is odd. A system of beliefs for Player B is a function $\pi^{t}: \mathcal{S}^{t} \rightarrow[0,1]$ for all $t$, interpreted as the probability that $B$ assigns to the event that he faces $\mathrm{A}_{H}$. The strate gies and Player B's beliefs must form a sequential equilibrium (SE); in addition, the restrictions imposed on beliefs off the equilibrium path must satisfy the intuitive criterion of Cho and Kreps (1987). ${ }^{6}$

We start the analysis with the case where B, the uninformed player, makes a combined offer based on his prior beliefs. Although our overall equilibrium strategies are substantially different from Rubinstein's (1985), part (i) of his theorem can be applied to this subgame, except that the pie here is of size two.

\footnotetext{
${ }^{5}$ The player who makes the first offer strictly prefers a combined offer while the other player is indifferent between the two types of offers. The second mover (Player B) is indifferent because, while he incurs a loss of utility from delay in agreement over the second pie, this loss is exactly offset by the advantage of making the first offer over that pie. Player A is strictly worse off because, in addition to delay in reaching agreement, he loses the first-mover advantage for the second pie. However, as we show below, preferences over the negotiation procedures may change dramatically if B does not know A's discount factor.

${ }^{6}$ Rubinstein's (1985) theorem characterizes what he calls a bar gaining sequential equilibrium (BSE) of the incomplete information bargaining game with one pie. The BSE concept imposes stronger conditions on off-the-equilibrium-path beliefs than does Cho and Kreps' Intuitive Criterion. See Admati and Perry (1987) for a discussion.
} 
Proposition 1 gives the relevant result. $^{7}$ As a first step, we define a critical value of prior beliefs by

$$
\bar{\pi}=\frac{\delta_{H}-\delta_{L}}{1-\delta_{L}+\delta_{\mathrm{B}}\left(1-\delta_{H}\right)} .
$$

PROPOSITION 1. Let $\pi<\bar{\pi}$. Then in any subgame in which B's beliefs are given by his priors, $B$ will make a combined offer of size $2 \delta_{L} z$, where

$$
z=\frac{\left(1-\delta_{\mathrm{B}}\right)\left(1+\pi \delta_{\mathrm{B}}\right)}{1-\delta_{L} \delta_{\mathrm{B}}-\pi \delta_{\mathrm{B}}\left(\delta_{\mathrm{B}}-\delta_{L}\right)}
$$

Hence, if it is sufficiently likely that the informed player is of type $A_{L}$ (i.e., $\pi<\bar{\pi}$ ), we have a separating SE where the uninformed player screens the informed player by observing the latter's acceptance choice in period 0 . Player $B$ concludes that he faces $A_{L}$ if the combined offer is accepted; otherwise a delay of one period occurs and B infers that he faces $\mathrm{A}_{H}$. Player B's expected screening payoff is $2(1-\pi)\left(1-\delta_{L} z\right)+2 \pi \delta_{\mathrm{B}}(1-z)$ where $z$ is given in (3). The expression defining $\bar{\pi}$ is obtained from the condition stating B's indifference between the screening offer mentioned in Proposition 1 and the non-screening offer $2\left(1-\delta_{\mathrm{B}}\right) /\left(1-\delta_{\mathrm{B}} \delta_{H}\right)$. Observe that $\bar{\pi} \rightarrow 1$ as $\delta_{H} \rightarrow 1$. Player B will always screen Player A as $A_{H}$ becomes very patient because the equilibrium non-screening payoff of $\mathrm{B}$ approaches zero. The cost of screening goes to zero while the benefit remains positive as $\delta_{H} \rightarrow 1$. Note also that $\bar{\pi}$ is decreasing in $\delta_{L}$ and $\delta_{B}$. Player B's cost of screening Player A increases as $\delta_{L}$ approaches $\delta_{H}$ (as the two types become one); $B$ may no longer take the risk of waiting one period when his payoff from the non-screening offer (accepted immediately by A) is almost twice the payoff he obtains from the screening offer (accepted by $A_{L}$ only). If, on the other hand, $\delta_{\mathrm{B}}$ is increased, B's non-screening payoff $2\left(1-\delta_{H}\right) /\left(1-\delta_{H} \delta_{\mathrm{B}}\right)$ increases faster than his screening payoff; as a result the interval $[0, \bar{\pi})$ gets smaller. B is therefore less likely to make a screening offer when he has more bargaining power.

Suppose now that Player A makes the first offer. We present in Proposition 2 a SE where $A_{H}$ and $\mathrm{B}$ reach an agreement on pie $X$ in period 0 and on pie $Y$ in period 1, whereas $\mathrm{B}$ and $\mathrm{A}_{L}$ agree on sharing both pies immediately. For future reference, we define a critical value of prior beliefs by

$$
\pi^{*} \equiv \frac{\left(1-\delta_{\mathrm{B}} \delta_{L}\right)\left(1+\delta_{H}^{2}\right)-2\left(1-\delta_{H} \delta_{\mathrm{B}}\right)}{\delta_{\mathrm{B}}\left[2\left(1-\delta_{H} \delta_{\mathrm{B}}\right)+\left(1+\delta_{H}^{2}\right)\left(\delta_{\mathrm{B}}-\delta_{L}\right)\right]} .
$$

\footnotetext{
${ }^{7}$ A proof of Proposition 1 based on the work by Shaked and Sutton (1984) is a vailable from the authors upon request.
} 
We shall assume that $\delta_{H}$ is sufficiently large so that $\pi^{*}>0$, i.e.,

$$
2\left(1-\delta_{H} \delta_{\mathrm{B}}\right)<\left(1-\delta_{\mathrm{B}} \delta_{L}\right)\left(1+\delta_{H}^{2}\right) .
$$

Another assumption we need for the SE presented in the following is

$$
2\left(1-\delta_{H} \delta_{\mathrm{B}}\right) \geq\left(1-\delta_{\mathrm{B}} \delta_{L}\right)\left(1+\delta_{L} \delta_{H}\right),
$$

which basically requires that $\delta_{L}$ be sufficiently smaller than $\delta_{H}$. In other words, the two types of A must be sufficiently heterogeneous in terms of their bargaining power. The discussion of the restrictions imposed on the discount factors by (A1), (A2), and $\pi^{*}$ is relegated to the end of this section, following the Proof of Proposition 2 where they are used. We need the following lemma.

LEMMA. $\pi^{*}<\bar{\pi}$.

The proof consists of algebraic manipulations of the definitions of $\pi^{*}$ and $\bar{\pi}$. It is omitted. The lemma implies that if $\pi<\pi^{*}$ and Player A makes a pooling offer, then Player B's strategies are as described in Proposition 1 for the case $\pi<\bar{\pi}$.

Proposition 2. Assume (A1), (A2) and let $\pi<\pi^{*}$. The following strategies constitute a (separating) sequential equilibrium.

Player $A_{H}$ offers a share of $X$ not less than $x=\left(1-\delta_{\mathrm{B}}\right) /\left(1-\delta_{H} \delta_{\mathrm{B}}\right)$ in period 0 , and makes a combined offer (on $X$ and $Y$ ) of size $x+y=2\left(1-\delta_{\mathrm{B}}\right) /\left(1-\delta_{H} \delta_{\mathrm{B}}\right)$ in even periods $t>0$. He accepts the single offer of at least $\delta_{H}\left(1-\delta_{\mathrm{B}}\right) /\left(1-\delta_{H} \delta_{\mathrm{B}}\right)$ and a combined offer of twice this single offer in every odd period.

Player $A_{L}$ makes a combined offer of $2\left(1-\delta_{\mathrm{B}}\right) /\left(1-\delta_{L} \delta_{\mathrm{B}}\right)$ in every even period but never makes a single offer. He accepts a single offer not less than $\delta_{L}\left(1-\delta_{\mathrm{B}}\right) /\left(1-\delta_{L} \delta_{\mathrm{B}}\right)$ or a combined offer of twice this single offer in odd periods.

Player B accepts at most the combined offer $2\left(1-\delta_{\mathrm{B}}\right) /\left(1-\delta_{L} \delta_{\mathrm{B}}\right)$. As for the single offers, he accepts at most $x=\left(1-\delta_{\mathrm{B}}\right) /\left(1-\delta_{H} \delta_{\mathrm{B}}\right)$ and offers $y=$ $\delta_{H}\left(1-\delta_{\mathrm{B}}\right) /\left(1-\delta_{H} \delta_{\mathrm{B}}\right)$ in the next period. If no agreement is reached before, Player $B$ makes a combined offer of $2 \delta_{L}\left(1-\delta_{\mathrm{B}}\right) /\left(1-\delta_{L} \delta_{\mathrm{B}}\right)$ in odd periods.

Player B's off-the-equilibrium-path beliefs satisfy the Cho-Kreps Intuitive Criterion. These beliefs are: All combined offers are interpreted as coming from $A_{L}$, while all single offers are interpreted as coming from $A_{H}$.

Proof. We first verify that $\mathrm{A}_{L}$ 's strategies are optimal at any date given the strategies of other players. The highest combined offer accepted by $\mathrm{B}$ is $2\left(1-\delta_{B}\right) /\left(1-\delta_{B} \delta_{L}\right)$. If, instead of making this combined offer, $\mathrm{A}_{L}$ imitates $\mathrm{A}_{H}$ and makes the single offer $\left(1-\delta_{\mathrm{B}}\right) /\left(1-\delta_{H} \delta_{\mathrm{B}}\right)$ in period $0, \mathrm{~B}$ accepts, revises beliefs to $\pi^{0}=1$, and offers $\delta_{H}\left(1-\delta_{\mathrm{B}}\right) /\left(1-\delta_{H} \delta_{\mathrm{B}}\right)$ in period 1 , which $\mathrm{A}_{L}$ will clearly accept. Imitating $\mathrm{A}_{H}$ 's strategy yields $\mathrm{A}_{L}$ the discounted payoff 
presented at the left-hand side of (4), while adopting the strategy described in the proposition yields the discounted payoff at the right-hand side of (4).

$$
\frac{\left(1-\delta_{\mathrm{B}}\right)\left(1+\delta_{H} \delta_{L}\right)}{1-\delta_{H} \delta_{\mathrm{B}}} \leq \frac{2\left(1-\delta_{\mathrm{B}}\right)}{1-\delta_{L} \delta_{\mathrm{B}}} .
$$

Since (4) holds by Assumption (A2), $\mathrm{A}_{L}$ will not imitate $\mathrm{A}_{H}$.

Consider now $A_{L}$ 's off-the-equilibrium-path offers. A single offer is interpreted as coming from $\mathrm{A}_{H}$. Clearly, if (4) holds, making an offer lower than $\mathrm{A}_{H}$ 's is strictly worse than making the combined equilibrium offer. On the other hand, any single offer higher than $A_{H}$ 's offer will be rejected by $B$, thus $\mathrm{A}_{L}$ would again be worse off. A combined offer is interpreted as coming from $\mathrm{A}_{L}$, so $\mathrm{A}_{L}$ will not deviate from $2\left(1-\delta_{\mathrm{B}}\right) /\left(1-\delta_{L} \delta_{\mathrm{B}}\right)$ because this is the highest combined offer that $\mathrm{B}$ accepts.

Consider Player $\mathrm{A}_{H}$. Given B's belief that a single offer can only come from $\mathrm{A}_{H}$, the best single offer that $\mathrm{A}_{H}$ can make in period 0 is $x=\left(1-\delta_{\mathrm{B}}\right) /\left(1-\delta_{H} \delta_{\mathrm{B}}\right)$, which is also the highest single offer that $\mathrm{B}$ accepts in the SPE of the bargaining game between $\mathrm{B}$ and $\mathrm{A}_{H}$. Finally, since $\mathrm{B}$ interprets any combined offer as coming from $A_{L}$, the highest combined offer that $B$ accepts is $A_{L}$ 's equilibrium offer: $2\left(1-\delta_{\mathrm{B}}\right) /\left(1-\delta_{\mathrm{B}} \delta_{L}\right)$. But $\mathrm{A}_{H}$ will not offer this because

$$
\frac{2\left(1-\delta_{\mathrm{B}}\right)}{1-\delta_{\mathrm{B}} \delta_{L}}<\frac{\left(1-\delta_{\mathrm{B}}\right)\left(1+\delta_{H}^{2}\right)}{1-\delta_{H} \delta_{\mathrm{B}}}
$$

or

$$
2\left(1-\delta_{\mathrm{B}} \delta_{H}\right)<\left(1+\delta_{H}^{2}\right)\left(1-\delta_{\mathrm{B}} \delta_{L}\right)
$$

by (A1). With these strategies of Player A, we have a separating SE: the game converts into a complete information game once $\mathrm{B}$ receives A's offer in period 0 . If $\mathrm{B}$ rejects $\mathrm{A}_{H}$ 's (single) offer, the subgame extending from period 1 is a complete information bargaining game as in Rubinstein (1982) with a pie of size 2 where the players' subgame-perfect equilibrium payoffs are $\left\{2 \delta_{H}^{2}\left(1-\delta_{\mathrm{B}}\right) /\left(1-\delta_{H} \delta_{\mathrm{B}}\right) ; 2 \delta_{\mathrm{B}}\left(1-\delta_{H}\right) /\left(1-\delta_{H} \delta_{\mathrm{B}}\right)\right\}$. Hence, accepting $\mathrm{A}_{H}$ 's single offer $x=\left(1-\delta_{\mathrm{B}}\right) /\left(1-\delta_{H} \delta_{\mathrm{B}}\right)$ in period 0 and offering $y=\delta_{H}\left(1-\delta_{\mathrm{B}}\right) /\left(1-\delta_{H} \delta_{\mathrm{B}}\right)$ in period 1 is optimal for B. Player B's postulated beliefs are consistent with the strategies presented above.

We still have to show that B's off-the-equilibrium-path beliefs satisfy Cho and Kreps' Intuitive Criterion. First, note that if $\mathrm{A}_{L}$ does not deviate to a single offer under the postulated beliefs, he will not deviate to a single offer under any other consistent belief system of B. Thus B's belief about single offers off the equilibrium path satisfy the criterion. Second, consider the combined offers off the equilibrium path. B's beliefs, as opposed to what was postulated in Proposition 2, must remain unchanged for all combined offers higher than $2\left(1-\delta_{\mathrm{B}}\right) /\left(1-\delta_{L} \delta_{\mathrm{B}}\right)$. Since $\pi<\pi^{*}$ (hence $\pi<\bar{\pi}$ by the lemma), both types 
of Player A make the combined offer $2 z$ in period 0 , where $z$ is given by (3). By Proposition 1, this is the highest offer acceptable to Player B, because in the subgame extending from his rejection, his agreements with $\mathrm{A}_{L}$ and $\mathrm{A}_{H}$ are respectively $2 \delta_{L} z$ in period 1 and $2 z$ in period 2 . However, it is not in the interest of $\mathrm{A}_{H}$ to make this combined offer because his payoff is higher under the SE described in Proposition 2:

$$
\frac{\left(1-\delta_{\mathrm{B}}\right)\left(1+\delta_{H}^{2}\right)}{1-\delta_{H} \delta_{\mathrm{B}}}>2 z
$$

since $\pi<\pi^{*}$ as assumed. Hence, beliefs that a combined offer can only come from $\mathrm{A}_{L}$ are intuitive.

Proposition 2 states that if B's prior belief that he faces $A_{H}$ is sufficiently low, and if the discount factors satisfy (A1), (A2), then a SE with rationalizing beliefs exists where $\mathrm{A}_{H}$ makes a single offer in period 0 and $\mathrm{B}$ accepts it. The agreement over the remaining pie is reached in period 1 with B's (single) offer. $\mathrm{A}_{L}$, on the other hand, makes a combined offer in period 0 and agreement is reached immediately. In this equilibrium $\mathrm{A}_{H}$ is restricting his offer to one issue in order to signal his barg aining power.

To have a better understanding of the restrictions imposed on the parameters of our model, it will be useful to combine (A1) and (A2) as in (5) below:

$$
1+\delta_{L} \delta_{H} \leq \frac{2\left(1-\delta_{\mathrm{B}} \delta_{H}\right)}{1-\delta_{L} \delta_{\mathrm{B}}}<1+\delta_{H}^{2} .
$$

The inequality on the left stems from (A2) and the one on the right from (A1). The set of conditions in Proposition 2 includes $\pi<\pi^{*}$, hence we also need to know whether $\pi^{*}>0$. However, this is already implied by (A1).

Let us therefore examine (5). First, the two inequalities in (5) show clearly the requirement that $\delta_{H}-\delta_{L}$ be large enough. In intuitive terms, a sufficient amount of heterogeneity is needed between the informed player's types to justify their differential equilibrium strategies. Second, the middle term in (5) is decreasing in $\delta_{\mathrm{B}}$. Hence, given $\delta_{H}>\delta_{L}$, the inequalities in (5) suggest that $\delta_{\mathrm{B}}$ must be contained in some interval. The upper bound $\bar{\delta}_{\mathrm{B}}$ of this interval can be obtained from the left, and the lower bound $\underline{\delta}_{\mathrm{B}}$ from the right-hand side of (5), with both sides holding with equality. We present these bounds below:

$$
\underline{\delta}_{\mathrm{B}}=\frac{1-\delta_{H}^{2}}{2 \delta_{H}-\delta_{L}\left(1+\delta_{H}^{2}\right)}<\delta_{\mathrm{B}} \leq \frac{1-\delta_{L} \delta_{H}}{2 \delta_{H}-\delta_{L}\left(1+\delta_{L} \delta_{H}\right)}=\bar{\delta}_{\mathrm{B}} .
$$

As expected, (6) shows that $\underline{\delta}_{\mathrm{B}}=\bar{\delta}_{\mathrm{B}}$ if $\delta_{H}=\delta_{L}$. The intuition for the existence of these two bounds is as follows. Recall that $\underline{\delta}_{\mathrm{B}}$ is obtained through (A1) which, if it holds with equality, is the condition stating $\mathrm{A}_{H}$ 's indifference between his single 
offer $\left(1-\delta_{\mathrm{B}}\right) /\left(1-\delta_{\mathrm{B}} \delta_{H}\right)$ and the low but combined offer $2\left(1-\delta_{\mathrm{B}}\right) /\left(1-\delta_{L} \delta_{\mathrm{B}}\right)$ of $\mathrm{A}_{L}$. The payoff corresponding to the latter offer increases faster than the former as the uninformed player becomes impatient (as $\delta_{\mathrm{B}}$ falls). And as $\delta_{\mathrm{B}}$ falls below the critical bound $\underline{\delta}_{\mathrm{B}}, \mathrm{A}_{H}$ deviates to $\mathrm{A}_{L}$ 's combined offer. We conclude that signalling by restricting one's offer to a single issue is not beneficial if the uninformed player is too "weak" (the share $\mathrm{A}_{H}$ gets by imitating $\mathrm{A}_{L}$ 's combined offer is large). On the other hand, if the uninformed player has too much bargaining power $\left(\delta_{\mathrm{B}} \geq \bar{\delta}_{\mathrm{B}}\right)$ then by the impact of $\delta_{\mathrm{B}}$ on equilibrium payoffs just mentioned, $A_{L}$ 's combined offer is too low so that he will be better off by imitating $\mathrm{A}_{H}$. Hence, the strong type of the informed player may not be able to make a signalling (single) offer if the uninformed player is too "strong".

The interval $\left(\underline{\delta}_{\mathrm{B}}, \bar{\delta}_{\mathrm{B}}\right]$ is obviously affected by $\delta_{H}$ and $\delta_{L}$. Differentiating the expressions for $\underline{\delta}_{\mathrm{B}}$ and $\bar{\delta}_{\mathrm{B}}$ in (6), we observe that both $\underline{\delta}_{\mathrm{B}}$ and $\bar{\delta}_{\mathrm{B}}$ are unambiguously decreasing in $\delta_{H}$ (the interval $\left(\underline{\delta}_{\mathrm{B}}, \bar{\delta}_{\mathrm{B}}\right]$ moves to the left). As $A_{H}$ has more bargaining power his equilibrium payoff gets larger, therefore $\bar{\delta}_{\mathrm{B}}$ must be lower to increase $\mathrm{A}_{L}$ 's equilibrium payoff as well. Otherwise $\mathrm{A}_{L}$ may deviate to $\mathrm{A}_{H}$ 's offer. The interpretation of $\partial \underline{\delta}_{\mathrm{B}} / \partial \delta_{H}<0$ follows a similar line of reasoning: $\underline{\delta}_{\mathrm{B}}$ must fall to prevent $\mathrm{A}_{H}$ from deviating to $\mathrm{A}_{L}$ 's combined offer. From (6) we also see that $\underline{\delta}_{\mathrm{B}}$ is increasing in $\delta_{L}$, but the effect of $\delta_{L}$ on $\bar{\delta}_{\mathrm{B}}$ is ambiguous. More precisely, we have $\partial \bar{\delta}_{\mathrm{B}} / \partial \delta_{L}<0$ if $1-\delta_{L^{2}}^{2} \delta_{H}^{2}<2 \delta_{H}\left(\delta_{H}-\delta_{L}\right)$, which holds for sure if $\delta_{H}$ is large enough. The sign of $\partial \delta_{\mathrm{B}} / \partial \delta_{L}$ is determined through the interplay of two opposing forces. Though the immediate share $A_{L}$ obtains from the two pies is increasing in $\delta_{L}$, so is the payoff he would get by choosing $\mathrm{A}_{H}$ 's issue-by-issue negotiation procedure. Clearly, $\mathrm{A}_{L}$ will choose the latter option if $\mathrm{A}_{H}$ 's equilibrium share is high enough, which corresponds to a high $\delta_{H}$. Since $\mathrm{A}_{L}$ has more incentives to imitate $\mathrm{A}_{H}$ as $\delta_{H}$ is higher, we must decrease $\delta_{\mathrm{B}}$ to eliminate these incentives, implying $\partial \bar{\delta}_{\mathrm{B}} / \partial \delta_{L}<0$. In fact, as $\delta_{H} \rightarrow 1$, we see from (6) that $\underline{\delta}_{\mathrm{B}} \rightarrow 0$ and $\bar{\delta}_{\mathrm{B}} \rightarrow 1 /\left(2+\delta_{L}\right)$, hence that $\bar{\delta}_{\mathrm{B}}$ is decreasing in $\delta_{L}$. It is also worth noting that $\pi^{*} \rightarrow 1$ as $\delta_{H} \rightarrow 1$. The SE payoff of $\mathrm{A}_{H}$ approaches the payoff he gets in the SPE under perfect information. As the strong type of the informed player becomes stronger, he will signal his type through single offers because this option becomes costless.

\section{CONCLUDING REMARKS}

We have shown that, as long as there is incomplete information about bargaining strength, players may engage in issue-by-issue negotiations even if (i) the issues are perfect substitutes and players are only concerned with maximizing their gains from settling the complete setof issues, and (ii) there are no transaction costs involved in negotiating a complete package. Our explanation thus complements the explanation provided by Fershtman (1990) and Busch and Horstmann (1992), namely, that differing preferences over individual issues play a role in 
determining negotiation agendas. Exploring the interactions between these two complementary explanations of issue-by-issue negotiations is one promising line of research. Another is the analysis of the interaction between multiple signalling and screening modes as, for instance, between signalling through delay in the style of Admati and Perry (1987) and through issue-restricted offers studied in this paper. A third extension would be to separate bargaining over the agenda from bargaining over issues, allowing some signalling to occur already at the agenda-setting stage.

\section{REFERENCES}

Admati, A. R., and Perry, M. (1987). "Strategic Delay in Bargaining," Rev. Econ. Stud. 54, 345-364. American Automobile Association (1992). Autotest 1993. Heathrow, FL: American Automobile Association.

Busch, L. A., and Horstmann, I. J. (1992). "Endogenous Incomplete Contracts,” mimeograph, University of Western Ontario.

Cho, I. K., and Kreps, D. (1987). "Signalling Games and Stable Equilibria," Quart. J. Econ. 52, 179-221.

Fershtman, C.(1990). "The Importance of the Agenda in Bargaining," Games Econ. Behav. 2, 224-238. Hart, O., and Moore, J.(1988). “Incomplete Contracts and Renegotiation,” Econometrica 56, 755-786. Huberman, G., and Kahn, C. (1988). "Limited Contract Enforcement and Renegotiation,” Amer. Econ. Rev. 78, 471-484.

Rubinstein, A. (1982). "Perfect Equilibrium in a Bargaining Model," Econometrica 50, 92-109.

Rubinstein, A. (1985). "A Bargaining Model with Incomplete Information about Time Preferences," Econometrica 53, 1151-1172.

Schelling, T. (1956). “An Essay on Bargaining,” Amer. Econ. Rev. 46, 281-306.

Shaked, A., and Sutton, J. (1984). "Involuntary Unemployment as a Perfect Equilibrium in a Bargaining Model,” Econometrica 52, 1351-1364.

Spier, K. (1992). "Incomplete Contracts and Signalling," RAND J. Econ. 23, 432-443. 